\title{
Autoimmune Disease-Associated Hypertension
}

\author{
Victoria L. Wolf ${ }^{1} \cdot$ Michael J. Ryan ${ }^{1,2}$ \\ Published online: 2 February 2019 \\ (C) The Author(s) 2019
}

\begin{abstract}
Purpose of Review To highlight important new findings on the topic of autoimmune disease-associated hypertension. Recent Findings Autoimmune diseases including systemic lupus erythematosus and rheumatoid arthritis are associated with an increased risk for hypertension and cardiovascular disease. A complex interaction among genetic, environmental, hormonal, and metabolic factors contribute to autoimmune disease susceptibility while promoting chronic inflammation that can lead to alterations in blood pressure. Recent studies emphasize an important mechanistic role for autoantibodies in autoimmune disease-associated hypertension. Moving forward, understanding how sex hormones, neutrophils, and mitochondrial dysfunction contribute to hypertension in autoimmune disease will be important.

Summary This review examines the prevalent hypertension in autoimmune disease with a focus on the impact of immune system dysfunction on vascular dysfunction and renal hemodynamics as primary mediators with oxidative stress as a main contributor.
\end{abstract}

Keywords Autoimmunity $\cdot$ Hypertension $\cdot$ Lupus $\cdot$ Inflammation $\cdot$ Renal hemodynamics $\cdot$ Vascular function

\section{Introduction}

Autoimmune disease is a major global health burden that affects approximately $5 \%$ of the population. For reasons that remain unclear, the prevalence of autoimmune diseases such as psoriasis, rheumatoid arthritis (RA), and systemic lupus erythematosus (SLE) has been increasing [1-3]. Cardiovascular disease is the leading cause of mortality, and its prevalence is markedly increased in patients with autoimmune diseases [4]. Hypertension is a major modifiable cardiovascular disease risk factor that is also prevalent in patients with autoimmune diseases [5, 6]. Despite the prevalent hypertension, guidelines for the management of hypertension do not consider patients with autoimmune disorders like SLE, causing practitioners to rely on the existing recommendations for

This article is part of the Topical Collection on Inflammation and Cardiovascular Diseases

Michael J. Ryan

mjryan@umc.edu

1 Department of Physiology \& Biophysics, University of Mississippi Medical Center, 2500 North State Street, Jackson, MS 39216-4505, USA

2 G.V. (Sonny) Montgomery Veterans Affairs Medical Center, Jackson, USA the general population while lacking data from large-scale clinical trials [7•]. Although anti-hypertensive medications are commonly indicated for patients with autoimmune disease, many patients are not prescribed the appropriate therapy, and those who are taking anti-hypertensive medications often have difficulty achieving guideline-recommended treatment targets [8]. Blood pressure is controlled by a complex, integrative network of physiological systems that involves renal, neurological, endocrine, and vascular mechanisms. Work from our laboratory and others suggests that innate and adaptive immunity are important regulators of these physiological systems and therefore have important mechanistic implications for the development of hypertension [9•, 10-12]. The purpose of this review is to highlight recent insights into how the chronic inflammation associated with autoimmunity may contribute to hypertension. Although multiple autoimmune diseases have prevalent hypertension and will be discussed herein, the major emphasis of this review will be on SLE, as a disease model of autoimmune-associated hypertension. More specifically, the review will focus on vascular dysfunction, renal hemodynamic mechanisms, and the role of oxidative stress. Several comprehensive reviews of the role that immunity has in the pathogenesis of hypertension are already available [13-15]. In addition, factors that may potentially serve as permissive mediators of autoimmune diseaseassociated hypertension will be discussed. 


\section{Hypertension Is Prevalent in Patients with Autoimmune Disease}

Clinical evidence shows that there is a strong association between autoimmune diseases like SLE and RA with hypertension [16]. For example, a large population-based study found an increased prevalence of hypertension in patients with RA (31\%) compared to the general population at $23 \%$ [17]. Several studies show an increased prevalence of hypertension in patients with SLE reaching as high as $40 \%$ of SLE patients under the age of 40 [18-20]. Similarly, patients with scleroderma have prevalent hypertension, especially when there is renal involvement [21]. Autoimmune disorders including SLE, RA, and scleroderma occur after a loss of immune tolerance with the subsequent production of autoantibodies. Interestingly, autoantibodies are associated with hypertension in patients with SLE, and primary hypertension is associated with an increase in serum immunoglobulins and increased antinuclear antibodies [22]. The presence of autoantibodies in patients with primary hypertension offers clues about the possible autoimmune underpinnings of the disease; however, we are just now beginning to understanding the link between autoimmunity and hypertension.

\section{Blood Pressure Control in Patients with Chronic Autoimmune Disease}

Despite an increased prevalence of hypertension and corresponding increase in cardiovascular risk, hypertension treatment guidelines do not consider the potential needs or challenges that might be unique to patients with autoimmune diseases like SLE, and drugs commonly used in the treatment of SLE have the potential to impact blood pressure [7•]. For example long-term use of glucocorticoids, non-selective NSAIDS and cyclooxygenase II inhibitors (coxibs), and some disease-modifying antirheumatic drugs (DMARD) are all associated with an increased risk for hypertension [16]. Part of the difficulty controlling blood pressure in patients with autoimmune disease may also be related to the prominent renal disease in patients with SLE. Approximately $40-70 \%$ of patients with SLE will develop chronic kidney disease (CKD) [23], and while upwards of $80 \%$ of patients with CKD have hypertension [24], only $13 \%$ have adequately controlled blood pressure [25]. Although no randomized-controlled trials have been performed, angiotensin converting enzyme (ACE) inhibitors are commonly prescribed for the treatment of hypertension and/or renal disease in SLE patients. The use of ACE inhibitors during SLE is generally well tolerated and associated with a delay in the onset of renal involvement and a decline in the risk of disease relapse in SLE patients [26] that likely occurs from both the decrease in angiotensin II and the immunomodulatory impact of renin-angiotensin system blockade. The premature development of atherosclerosis is less frequent among SLE patients using ACE inhibitors [27]. Nevertheless, the appropriate initiating drug for blood pressure control, combinations of drugs, and the potential impact of immunomodulatory therapies on blood pressure in this patient population has not been carefully examined.

\section{Risk Factors for Autoimmune Disease and Hypertension}

Both SLE and hypertension are multifactorial diseases. Therefore, it may not be surprising that there is overlap among genetic and environmental risk factors for the development of autoimmune diseases and hypertension. For example, smoking and body mass index (BMI) associated with poor outcomes for patients with SLE and with the risk of developing hypertension [6, 28-30]. However, patients with SLE have an increased risk for CVD mortality beyond traditional risk factors, suggesting that disease-specific factors play an important role [31]. Below, some of the SLE-specific risk factors, which contribute to SLE susceptibility and likely contribute to the increased prevalence of hypertension, are discussed.

\section{Genetic Factors}

Numerous susceptibility genes have been identified in the pathogenesis of autoimmune diseases. Studies in the NZM2410 model of SLE in 1994 by Morel et al. led to the identification of three susceptibility loci, Sle1-3, that have a significant correlation with the development of immunecomplex-mediated glomerulonephritis in murine strains [32]. Studies have been done to link insertion/deletion polymorphisms in the gene for ACE to SLE, lupus nephritis, and vascular changes; although, no strong correlation has been identified [33-35]. Similar studies have shown no definitive correlations in patients with systemic sclerosis [36]. HLADR4, DR $\beta 1$, protein tyrosine phosphatase 22 , and peptidyl arginine deiminase 4 (PADI4) are among the genes identified with an association for an increased susceptibility in patients with RA [37]. One recent study also suggests an association with PADI4 gene polymorphisms and patients with SLE with additional PADI4 polymorphisms conferring an increased risk of renal involvement in the form of lupus nephritis [38]. PADI4 is an enzyme responsible for the conversion of arginine to citrulline residues, which is an important step in the process of NETosis. NETosis will be discussed in more detail later on as it pertains to the formation of oxidative stress. Although these susceptibility genes have a known association with immune system dysfunction in autoimmunity, it is not clear how or if these susceptibility genes contribute to the development of hypertension. 


\section{Environmental Factors}

Environment/gene interactions that increase autoimmune disease susceptibility have been studied for many years and the understanding of these interactions continues to evolve [28, 39]. Recently, vitamin D deficiency has been reported in many patients with autoimmune disease [40-42]. Vitamin D deficiency in patients with SLE is linked to prevalent renal disease, in addition to lifestyle modifications (sunlight avoidance due to photosensitivity) and medications (long-term use of corticosteroids) [43]. Potential mechanisms by which vitamin D deficiency may contribute to the pathogenesis of SLE include an associated decrease in regulatory $\mathrm{T}$ cells $\left(\mathrm{T}_{\mathrm{REG}}\right)$, which are essential for immune tolerance against self-antigens, and increased activation of autoreactive B cells, contributing to an increased generation of autoantibodies [44]. The immunomodulatory properties of vitamin $\mathrm{D}$ are mediated by vitamin $\mathrm{D}_{3}$ receptors (VDR) found on multiple immune cell lineages (monocytes, dendritic cells, and activated T cells) [45]. In addition to the known link between vitamin D deficiency and immune system activation, there is evidence for an association between vitamin $\mathrm{D}$ deficiency and an increased risk for hypertension and cardiovascular disease [43]. A recent study by Sabio et al. reported that there is a strong association between non-dipper hypertension and vitamin D deficiency in women with SLE [46]. Non-dipper hypertension is defined as the absence of a normal $10 \%$ physiological decline in blood pressure that occurs at night, and is linked with a greater risk of developing cardiovascular disease (as summarized in this review [47]). Going forward, it will be important to continue identifying and understanding the mechanisms by which environmental factors like vitamin D deficiency can modulate autoimmunity and the associated risk for developing hypertension.

\section{Sex-Specific Factors}

The idea that the immune system can impact blood pressure in a sex-dependent manner is supported by numerous studies (summarized in these recent reviews [48-50]). Sex hormones, including estrogen and testosterone, have immunomodulatory functions and are often implicated in the strong female sex bias associated with autoimmune diseases like SLE and RA. In experimental models of autoimmunity, the manipulation of sex hormones has been shown to modify the pathogenesis and progression of disease. Estrogen (via ER $\alpha$ ) has long been the primary focus of researchers trying to understand the sex bias in SLE; however, a recent study challenged the notion that complete knockout of $\mathrm{ER} \alpha$ is directly protective in murine lupus [51•]. Scott et al. demonstrated that NZM/ER $\alpha$ KO mice were not protected from renal disease following ovariectomy [51•], a finding that suggests other ovarian hormones might confer protection in the absence of ER $\alpha$. Continuing to understand the role of estrogens during SLE and the potential regulation of blood pressure in these women will be an important pursuit. Estrogens are typically thought to confer protection against cardiovascular risk factors like hypertension because women have a lower prevalence of hypertension than men until they reach menopause [52]. The complex role of estrogens during SLE was further illustrated by work from our own laboratory showing that ovariectomy in adult female mice with SLE (30-week old NZBWF1) exacerbates hypertension and albuminuria [53], whereas ovariectomy performed in young female NZBWF1 mice (10 weeks old) delays the production of autoantibodies and onset of albuminuria without impacting blood pressure [54]. These data suggest that estrogen has a complicated temporal role in the pathogenesis of SLE and the associated hypertension.

\section{Metabolic Factors}

Autoimmune diseases like SLE are commonly associated with metabolic changes including insulin resistance and dyslipidemia [55]. Adipokines are pleiotropic factors secreted by white adipose tissue that may contribute to chronic low-grade inflammation in autoimmune disease [56]. Adipokines like leptin, adiponectin, visfatin, and resistin have been identified as potential mediators of metabolic syndrome and associated with insulin resistance, central obesity, dyslipidemia, and hypertension in autoimmune disease. Leptin is a known immunomodulatory hormone and has also been shown to impact blood pressure through changes in sympathetic outflow and renal sodium retention [57]. There is now emerging evidence to suggest that leptin has proinflammatory effects in multiple autoimmune disease including SLE, RA, and multiple sclerosis (MS) [58]. Hyperleptinemia in SLE patients correlates directly with disease activity and inversely with numbers of circulating $\mathrm{T}_{\mathrm{REG}}$. $\mathrm{T}_{\mathrm{REG}}$ are critical for maintaining immunological tolerance to prevent autoimmunity, and a deficiency in $\mathrm{T}_{\mathrm{REG}}$ has been linked with the development of hypertension [59•]. The known connections to the regulation of both immune and cardiovascular function highlight the need to study leptin, and other metabolic factors, and to understand both their mechanistic importance and value as therapeutic targets in autoimmune-associated hypertension.

\section{Immune System Dysfunction: The Role of B and T Cells}

Recent studies from our laboratory demonstrated a key mechanistic role of immune system dysfunction in hypertension associated with autoimmunity in the NZBWF1 female mouse model of SLE $[10,11,60]$. The depletion of B cells with anti-CD20 antibodies (the mouse equivalent of rituximab) [60] and mycophenolate mofetil (MMF) [11] attenuated hypertension in this mouse model. Importantly, both rituximab and MMF are used clinically in human patients with SLE $[61,62]$ and MMF has been shown to reduce blood pressure in small clinical studies in 
humans [63]. A more recent study from our laboratory addressed the question of whether autoantibodies mechanistically contribute to the pathogenesis of hypertension during autoimmune disease. In that study, Taylor et al. utilized the proteasome inhibitor bortezomib to deplete plasma cells and demonstrated the importance of circulating immunoglobulins to the pathogenesis of hypertension during autoimmunity [9॰]. Bortezomib is a selective inhibitor of the $26 \mathrm{~S}$ proteasome and induces cell death by activating the terminal unfolded protein response. Plasma cells are hypersensitive to proteasome inhibition compared to other cell types because of their extremely high rate of protein biosynthesis [64].

In humans and in experimental animal models, there is a decrease in circulating $T_{\text {REG }}$ cells that is linked to the development of SLE [65-70]. Adoptive transfer of $\mathrm{T}_{\text {REG }}$ in lupus-prone mice results in delayed disease progression, reduced renal pathology, and increased survival [71]. Similarly, adoptively transferring $\mathrm{T}_{\mathrm{REG}}$ into experimental models of hypertension reduces blood pressure [72-74]. These studies further strengthen the link between autoimmunity and blood pressure control. A recent study from our laboratory indirectly supports the concept that expanding $\mathrm{T}_{\mathrm{REG}}$ during SLE may attenuate autoimmuneassociated hypertension [10]. Treatment with an anti$\mathrm{CD} 3 \varepsilon$ antibody, which has been utilized to induce peripheral immune tolerance and expand $\mathrm{T}_{\mathrm{REG}}$ cells in small clinical studies [75], attenuated the hypertension in female SLE mice [10]. Although there are currently no studies directly testing whether expansion of the $T_{\text {REG }}$ population attenuates hypertension during SLE, Liu et al. [76] reported that CD8+i $\mathrm{T}_{\mathrm{REG}}$ attenuate LPSinduced glomerular endothelial cell injury in female MRL/lpr lupus-prone mice by inhibiting p38 MAPK and the NF- $\mathrm{kB}$ pathway. The role of $\mathrm{CD} 8+\mathrm{i} \mathrm{T}_{\mathrm{REG}}$ and other $\mathrm{T}$ cell subsets in autoimmune disease-associated hypertension remains to be examined. Interleukin-17A (IL-17A) is a proinflammatory cytokine produced predominantly by CD4+ T-helper 17 cells as well as $\gamma \delta \mathrm{T}$ cells that play a potentially important role in autoimmune diseases. Solak et al. recently demonstrated that IL-17A mediates AngII-induced renal injury and regulates renal sodium transporters, NHE3 and sodium-chloride cotransporter (NCC), via an SGK1-dependent pathway [77]. This study provided mechanistic insight into how inflammatory cytokines like IL-17A can regulate sodium and water homeostasis and blood pressure [77].

\section{Vascular Dysfunction}

Numerous studies reported that patients with SLE or RA exhibit impaired vascular function as measured by endothelial dependent, flow-mediated dilatation $[78,79]$. A recent study found that RA disease duration is a predictor of vascular stiffness as measured by carotid to femoral pulse wave velocity (cfPWV) [80]. Similarly, a meta-analysis from patients with primary Sjogren's syndrome showed a significant increase in pulse wave velocity and intima media thickness suggestive of arterial stiffness and subclinical atherosclerosis [81]. In SLE, circulating autoantibodies and other inflammatory mediators can activate endothelial cells to express cell adhesion molecules [82, 83]. Endothelial cell adhesion molecules (ECAMS), such as vascular cellular adhesion molecule-1 (VCAM-1) and intracellular adhesion molecule-1 (ICAM-1), are transmembrane proteins that may be important mediators in the migrations of immune cells from the circulation to tissues affected by inflammation [84]. Increased serum and urine levels of VCAM-1 and ICAM- 1 have been found in patients with active SLE [85-87], and ECAMs are a typical finding on the histopathology of glomerular lesions in MRL/lpr mice [88]. Overall, the infiltration of immune cells and impact of inflammatory cytokines on vascular function during SLE as it related to the development of hypertension during autoimmunity is an open area of investigation. It is well known that vascular dysfunction is associated with the development of hypertension and that renal vascular dysfunction in particular can directly cause hypertension.

\section{Renal Hemodynamics}

Body salt and fluid homeostasis and are essential for normal blood pressure control, and renal hemodynamic changes that lead to increased sodium and water reabsorption and extracellular fluid volume underlie the development of hypertension. Renal involvement in SLE typically occurs in 50-75\% of patients in form of immune complex mediated glomerulonephritis [89]. The nephritis often results from extra-glomerular immune deposits found in the tubular basement membranes, the interstitium, and blood vessels [90]. The renal injury per se that is caused by nephritis is likely not the cause of the hypertension. This is supported by studies showing that hypertension is prevalent in childonset SLE independent of the presence of nephritis [91]. In addition, Shaharir et al. found that 53\% of SLE patients were hypertensive without evidence of nephritis [20]. Consistent with human data, our laboratory recently reported that hypertension is not associated with markers of renal injury, including albuminuria and glomerulosclerosis in the NZBWF1 female mouse model of SLE [9•]. Taken together, both clinical data and data from experimental animal models suggest the possibility that early immunological changes during autoimmunity may impact renal hemodynamic and tubular function to cause hypertension before there are clear signs of renal injury.

\section{Alterations in Glomerular Filtration Rate and Renal Blood Flow}

Surprisingly, little is known about how the immunological changes that occur in patients with autoimmune disease 
directly impact renal hemodynamic function and increase the risk of developing hypertension. Clinical data show impairments in both GFR and renal plasma flow (measured using urinary clearance methods) in SLE patients with active and inactive lupus nephritis [92]. Although few studies have focused on renal hemodynamic changes in SLE in recent years, Mori et al. found that out of 1908 patients with RA identified in Japanese community hospitals, $33.8 \%$ had renal dysfunction with absolute eGFR $<60 \mathrm{ml} / \mathrm{min}$, and $2.1 \%$ of patients had severe or end-stage kidney disease with absolute eGFR < $30 \mathrm{ml} / \mathrm{min}$ [93]. Of the patients diagnosed with renal dysfunction, $60.1 \%$ were classified as hypertensive (systolic blood pressure $\geq 140 \mathrm{mmHg}$ ) compared to $26.3 \%$ without renal dysfunction [93]. Another study reported that the 20-year cumulative incidence of reduced kidney function was significantly higher in RA patients compared to non-RA patients [94]. Evidence that renal inflammation is a key element in the role of the kidney in the pathogenesis of hypertension has been reviewed recently by Bernardo Rodriguez-Iturbe [13]. A study by Franco et al. found that AngII hypertension was associated with renal inflammation with a high salt diet and resulted in increased afferent and efferent glomerular vasoconstriction and a reduction in renal plasma flow and single nephron GFR [95]. MMF treatment offered protection in the AngII-salt-sensitive hypertensive rat model by correcting glomerular hemodynamics in association with immunosuppression [95]. Still, the specific immunological mediators that alter renal function during autoimmune diseases and the timing of the changes have not been clearly elucidated.

\section{Renin-Angiotensin System}

The renin-angiotensin system (RAS) is widely recognized for its role in blood pressure control and is also recognized for its role as a proinflammatory mediator. Therefore, RAS blockade in patients with autoimmune disease may have dual effects in managing autoimmune disease and its associated hypertension. A study from our laboratory showed the renal vascular sensitivity to AngII is enhanced in female NZBWF1 mice with SLE suggesting a direct impact of autoimmunity on AngII-mediated renal hemodynamic function [96]. In a more recent study, Yue et al. found that early (within 3 months after kidney biopsy) blockade of the RAS in SLE patients with antiphospholipid-associated nephropathy (aPLN) improved both short- (12 months after kidney biopsy) and long-term (a mean follow-up of 80 months) renal outcomes like improvement ratio of eGFR [97]. Interestingly, blood pressure was not adequately controlled by RAS blockade in this patient population and the renal improvements occurred independently of changes in blood pressure or albuminuria. Thus, despite the usage of RAS blockade as an initiator for blood pressure control during SLE, a large knowledge gap remains for understanding the best clinical practices for treating hypertension in these patients.

\section{Oxidative Stress}

Reactive oxygen species (ROS), such as superoxide anion, hydrogen peroxide, and hydroxyl anion, are known to play a major role in the tissue damage associated with autoimmune disease and in the development of hypertension $[98,99]$. The impact of ROS on renal function and the development of hypertension have been extensively reviewed [15]; however, less is understood about the impact of ROS on autoimmune-associated hypertension.

\section{Neutrophils}

Neutrophils are specialized phagocytic cells of the innate immune system that play a key role in the release of ROS during an autoimmune inflammatory response [100]. The main source of ROS in neutrophils is NADPH oxidase 2 (NOX2); however, mitochondrial ROS are likely a major source of tissue damage resulting from activation of the inflammasome and neutrophil extracellular trap (NET) formation [100]. NETosis is a cell death pathway, similar to apoptosis, characterized by extrusion of chromatin bound to cytosolic and granular content, and is a normal host defense mechanism designed to trap and kill microorganisms. NETs and NETing neutrophils are found in the kidneys of patients with SLE, where they can be a source of nuclear antigens [101]. Lowdensity granulocytes (LDGs) present in peripheral blood mononuclear cell (PBMC) fractions of lupus patients reportedly have a propensity to form NETs, which promote vascular leakage and endothelial dysfunction through the degradation of vascular endothelial cadherin and subsequent activation of $\beta$-cadherin signaling $[102,103 \bullet]$. Another study reported a correlation between renal involvement in SLE and impaired NET degradation that is associated with altered DNase1 function [104]. Whether impaired degradation of NETs represents an important early signal for the development of autoantibodies that can promote hypertension, or directly increases oxidative stress in the renal vasculature and tubules to promote hypertension has not been addressed experimentally.

\section{Mitochondrial Dysfunction}

Apoptosis and NETosis are both energy-consuming processes that require mitochondria as an energy source, and mitochondria are a major cellular source of intracellular ROS generation [105]. Growing evidence suggests a role for mitochondrial dysfunction and the subsequent generation of ROS in diabetic nephropathy and chronic kidney disease [106]; however, very little is understood about renal mitochondrial dysfunction during SLE and its potential role in the pathogenesis of hypertension. T cells from patients with SLE are reported to exhibit mitochondrial 
hyperpolarization, increased ROS production, diminished intracellular glutathione (GSH) levels, cytoplasmic alkalization, and adenosine triphosphate (ATP) depletion that causes diminished activation-induced apoptosis and sensitizes lupus $\mathrm{T}$ cells to necrosis [107]. Given the role of T cell subset in SLE disease progression, and evidence pointing to a role for $\mathrm{T}$ cells in the development of hypertension, it will ultimately be important to understand the impact of mitochondrial dysfunction in these and other immune cells on physiological systems that ultimately control blood pressure.

\section{Conclusions}

The management of high blood pressure in patients with autoimmune disease should be considered a major aspect of their treatment plan. In this review, we have provided an update on some of the disease-specific factors that contribute to the prevalent hypertension of autoimmunity. Recent studies from our laboratory have highlighted the important role of the adaptive immune system in the development of hypertension in an experimental mouse model of SLE. Future studies should explore the impact of immune cell infiltration in the kidney to promote changes in renal hemodynamics. Neutrophils, impaired NET degradation, and mitochondrial dysfunction may lead to the formation of auto-antigens and the production of ROS that could promote changes in glomerular filtration rate, renal vascular resistance, and renal blood flow, ultimately leading to hypertension, and an increased risk for cardiovascular and renal disease.

Funding Information This study was funded by VA Merit Award (BX002604-0 1A2) to MJR, AHA 18PRE34020108 to VLW, NIH (P01HL051971, P20GM104357, U54GM115428, R01HL134711, T32HL105324-05) to UMMC Physiology.

\section{Compliance with Ethical Standards}

Conflict of Interest Dr. Ryan reports grants from Veterans Affairs, grants from NIH, grants from AHA, during the conduct of the study. Dr. Wolf declares no conflicts of interest relevant to this manuscript.

Human and Animal Rights and Informed Consent This article does not contain any studies with human or animal subjects performed by any of the authors.

Open Access This article is distributed under the terms of the Creative Commons Attribution 4.0 International License (http:// creativecommons.org/licenses/by/4.0/), which permits unrestricted use, distribution, and reproduction in any medium, provided you give appropriate credit to the original author(s) and the source, provide a link to the Creative Commons license, and indicate if changes were made.

Publisher's Note Springer Nature remains neutral with regard to jurisdictional claims in published maps and institutional affiliations.

\section{References}

Papers of particular interest, published recently, have been highlighted as:

- Of importance

1. Rees F, DohertyM,Grainge MJ, Lanyon P, ZhangW. The worldwide incidence and prevalence of systemic lupus erythematosus: a systematic review of epidemiological studies. Rheumatology (Oxford). 2017;56(11):1945-61. https://doi.org/10.1093/rheumatology/kex260.

2. Carter EE, Barr SG, Clarke AE. The global burden of SLE: prevalence, health disparities and socioeconomic impact. Nat Rev Rheumatol. 2016;12(10):605-20. https://doi.org/10.1038/nrrheum. 2016.137.

3. Barbour KE, Helmick CG, Boring M, Brady TJ. Vital signs: prevalence of doctor-diagnosed arthritis and arthritis-attributable activity limitation - United States, 2013-2015. MMWR Morb Mortal Wkly Rep. 2017;66(9):246-53. https://doi.org/10.15585/mmwr. mm6609e1.

4. Giannelou M, Mavragani CP. Cardiovascular disease in systemic lupus erythematosus: a comprehensive update. J Autoimmun. 2017;82:1-12. https://doi.org/10.1016/j.jaut.2017.05.008.

5. Panoulas VF, Douglas KM, Milionis HJ, Stavropoulos-Kalinglou A, Nightingale P, Kita MD, et al. Prevalence and associations of hypertension and its control in patients with rheumatoid arthritis. Rheumatology (Oxford). 2007;46(9):1477-82. https://doi.org/10. 1093/rheumatology/kem169.

6. Neimann AL, Shin DB, Wang X, Margolis DJ, Troxel AB, Gelfand JM. Prevalence of cardiovascular risk factors in patients with psoriasis. J Am Acad Dermatol. 2006;55(5):829-35. https:// doi.org/10.1016/j.jaad.2006.08.040.

7. Tselios K, Koumaras C, Urowitz MB, Gladman DD. Do current arterial hypertension treatment guidelines apply to systemic lupus erythematosus patients? a critical appraisal. Semin Arthritis Rheum. 2014;43(4):521-5. https://doi.org/10.1016/j.semarthrit. 2013.07.007 This review serves as a commentary on the application of current hypertension guidelines (as of 2014) to patients with SLE. The authors recommend anti-hypertensive therpay at levels of $140 / 90 \mathrm{mmHg}$ in newly diagnosed SLE patients without overt target organ involvement. In patients with lupus nephritis, therapy should be inidicated at lower systolic and diastolic pressures $(130 / 80 \mathrm{mmHg})$. Optimal blood pressure levels are less than $130 / 80 \mathrm{mmHg}$ in hypertensive SLE patients.

8. Ikdahl E, Wibetoe G, Rollefstad S, Salberg A, Bergsmark K, Kvien $\mathrm{TK}$, et al. Guideline recommended treatment to targets of cardiovascular risk is inadequate in patients with inflammatory joint diseases. Int J Cardiol. 2018;274:311-8. https://doi.org/10.1016/j.ijcard.2018. 06.111 .

9. Taylor EB, Barati MT, Powell DW, Turbeville HR, Ryan MJ. Plasma cell depletion attenuates hypertension in an experimental model of autoimmune disease. Hypertension. 2018;71(4):719-28. https://doi.org/10.1161/HYPERTENSIONAHA.117.10473 Results demonstrate that the production of autoantibodies by plasma cells mechanistically contributes to hypertension in an experimental model of SLE independently of renal injury. These findings suggest a potential role for circulating immunoglobulins in primary hypertension.

10. Mathis KW, Taylor EB, Ryan MJ. Anti-CD3 antibody therapy attenuates the progression of hypertension in female mice with systemic lupus erythematosus. Pharmacol Res. 2017;120:252-7. https://doi.org/10.1016/j.phrs.2017.04.005.

11. Taylor EB, Ryan MJ. Immunosuppression with mycophenolate mofetil attenuates hypertension in an experimental model of 
autoimmune disease. J Am Heart Assoc. 2017;6(3). https://oi. org/10.1161/JAHA.116.005394.

12. Rodriguez-Iturbe B, Pons H, Johnson RJ. Role of the immune system in hypertension. Physiol Rev. 2017;97(3):1127-64. https://doi.org/10.1152/physrev.00031.2016.

13. Rodriguez-Iturbe B. Autoimmunity in the pathogenesis of hypertension. Hypertension. 2016;67(3):477-83. https://doi.org/10. 1161/HYPERTENSIONAHA.115.06418.

14. Small HY, Migliarino S, Czesnikiewicz-Guzik M, Guzik TJ. Hypertension: focus on autoimmunity and oxidative stress. Free Radic Biol Med. 2018;125:104-15. https://doi.org/10.1016/j. freeradbiomed.2018.05.085.

15. Solak Y, Afsar B, Vaziri ND, Aslan G, Yalcin CE, Covic A, et al. Hypertension as an autoimmune and inflammatory disease. Hypertens Res. 2016;39(8):567-73. https://doi.org/10.1038/hr.2016.35.

16. Panoulas VF, Metsios GS, Pace AV, John H, Treharne GJ, Banks MJ, et al. Hypertension in rheumatoid arthritis. Rheumatology (Oxford). 2008;47(9):1286-98. https://doi.org/10.1093/ rheumatology/ken 159 .

17. Han C, Robinson DW Jr, Hackett MV, Paramore LC, Fraeman $\mathrm{KH}$, Bala MV. Cardiovascular disease and risk factors in patients with rheumatoid arthritis, psoriatic arthritis, and ankylosing spondylitis. J Rheumatol. 2006;33(11):2167-72.

18. Al-Herz A, Ensworth S, Shojania K, Esdaile JM. Cardiovascular risk factor screening in systemic lupus erythematosus. J Rheumatol. 2003;30(3):493-6.

19. Sabio JM, Vargas-Hitos JA, Navarrete-Navarrete N, Mediavilla JD, Jimenez-Jaimez J, Diaz-Chamorro A, et al. Prevalence of and factors associated with hypertension in young and old women with systemic lupus erythematosus. J Rheumatol. 2011;38(6): 1026-32. https://doi.org/10.3899/jrheum.101132.

20. Shaharir SS, Mustafar R, Mohd R, Mohd Said MS, Gafor HA. Persistent hypertension in lupus nephritis and the associated risk factors. Clin Rheumatol. 2015;34(1):93-7. https://doi.org/10. 1007/s10067-014-2802-0.

21. Shanmugam VK, Steen VD. Renal manifestations in scleroderma: evidence for subclinical renal disease as a marker of vasculopathy. Int J Rheumatol. 2010;2010:1-8. https://doi.org/10.1155/2010/538589.

22. Jafri S, Ormiston ML. Immune regulation of systemic hypertension, pulmonary arterial hypertension, and preeclampsia: shared disease mechanisms and translational opportunities. Am J Physiol Regul Integr Comp Physiol. 2017;313(6):R693-r705. https://doi. org/10.1152/ajpregu.00259.2017.

23. Mohan C, Putterman C. Genetics and pathogenesis of systemic lupus erythematosus and lupus nephritis. Nat Rev Nephrol. 2015;11(6):329-41. https://doi.org/10.1038/nrneph.2015.33.

24. Judd E, Calhoun DA. Management of hypertension in CKD: beyond the guidelines. Adv Chronic Kidney Dis. 2015;22(2):11622. https://doi.org/10.1053/j.ackd.2014.12.001.

25. Sarafidis PA, Li S, Chen SC, Collins AJ, Brown WW, Klag MJ, et al. Hypertension awareness, treatment, and control in chronic kidney disease. Am J Med. 2008;121(4):332-40. https://doi.org/ 10.1016/j.amjmed.2007.11.025.

26. Duran-Barragan S, McGwin G Jr, Vila LM, Reveille JD, Alarcon GS, cohort LamU. Angiotensin-converting enzyme inhibitors delay the occurrence of renal involvement and are associated with a decreased risk of disease activity in patients with systemic lupus erythematosus-results from LUMINA (LIX): a multiethnic US cohort. Rheumatology (Oxford). 2008;47(7):1093-6. https://doi. org/10.1093/rheumatology/ken208.

27. Ravenell RL, Kamen DL, Spence JD, Hollis BW, Fleury TJ, Janech MG, et al. Premature atherosclerosis is associated with hypovitaminosis D and angiotensin-converting enzyme inhibitor non-use in lupus patients. Am J Med Sci. 2012;344(4):268-73. https://doi.org/10.1097/MAJ.0b013e31823fa7d9.
28. Barbhaiya M, Costenbader KH. Environmental exposures and the development of systemic lupus erythematosus. Curr Opin Rheumatol. 2016;28(5):497-505. https://doi.org/10.1097/bor. 0000000000000318 .

29. Teh P, Zakhary B, Sandhu VK. The impact of obesity on SLE disease activity: findings from the Southern California Lupus Registry (SCOLR). Clin Rheumatol. 2018. https://doi.org/10. 1007/s10067-018-4336-3.

30. Speyer CB, Costenbader KH. Cigarette smoking and the pathogenesis of systemic lupus erythematosus. Expert Rev Clin Immunol. 2018;14(6):481-7. https://doi.org/10.1080/1744666x. 2018.1473035

31. Ku IA, Imboden JB, Hsue PY, Ganz P. Rheumatoid arthritis: model of systemic inflammation driving atherosclerosis. Circ J. 2009;73(6):977-85.

32. Morel L, Rudofsky UH, Longmate JA, Schiffenbauer J, Wakeland EK. Polygenic control of susceptibility to murine systemic lupus erythematosus. Immunity. 1994;1(3):219-29.

33. Kaufman KM, Kelly J, Gray-McGuire C, Asundi N, Yu H, Reid J, et al. Linkage analysis of angiotensin-converting enzyme (ACE) insertion/deletion polymorphism and systemic lupus erythematosus. Mol Cell Endocrinol. 2001;177(1-2):81-5.

34. Lee YH, Choi SJ, Ji JD, Song GG. Association between the angiotensin-converting enzyme insertion/deletion polymorphism and susceptibility to systemic lupus erythematosus: a meta-analysis. J Renin-Angiotensin-Aldosterone Syst. 2013;14(3):248-54. https://doi.org/10.1177/1470320312459979.

35. Lee YH, Rho YH, Choi SJ, Ji JD, Song GG. Angiotensin-converting enzyme insertion/deletion polymorphism and systemic lupus erythematosus: a metaanalysis. J Rheumatol. 2006;33(4):698-702.

36. Joung CI, Park YW, Kim SK, Uhm WS, Kim TH, Yoo DH. Angiotensin-converting enzyme gene insertion/deletion polymorphism in Korean patients with systemic sclerosis. J Korean Med Sci. 2006;21(2):329-32. https://doi.org/10.3346/jkms.2006.21.2.329.

37. Van Raemdonck K, Umar S, Szekanecz Z, Zomorrodi RK, Shahrara S. Impact of obesity on autoimmune arthritis and its cardiovascular complications. Autoimmun Rev. 2018;17(8): 821-35. https://doi.org/10.1016/j.autrev.2018.02.007.

38. Massarenti L, Enevold C, Damgaard D, Odum N, Nielsen CH, Jacobsen S. Peptidylarginine deiminase-4 gene polymorphisms are associated with systemic lupus erythematosus and lupus nephritis. Scand J Rheumatol. 2018:1-8. https://doi.org/10.1080/ 03009742.2018.1488273.

39. Zhang P, Lu Q. Genetic and epigenetic influences on the loss of tolerance in autoimmunity. Cell Mol Immunol. 2018;15(6):57585. https://doi.org/10.1038/cmi.2017.137.

40. Ruiz-Irastorza G, Egurbide MV, Olivares N, Martinez-Berriotxoa A, Aguirre C. Vitamin D deficiency in systemic lupus erythematosus: prevalence, predictors and clinical consequences. Rheumatology (Oxford). 2008;47(6):920-3. https://doi.org/10. 1093/rheumatology/ken121.

41. Haque UJ, Bathon JM, Giles JT. Association of vitamin D with cardiometabolic risk factors in rheumatoid arthritis. Arthritis Care Res (Hoboken). 2012;64(10):1497-504. https://doi.org/10.1002/ acr.21715.

42. Gao CC, Liu SY, Wu ZZ, Li TF, Gao GM, Liu ZS, et al. Severe vitamin $\mathrm{D}$ deficiency increases the risk for moderate to severe disease activity in Chinese patients with SLE. Lupus. 2016;25(11):1224-9. https://doi.org/10.1177/0961203316635289.

43. Mak A. The impact of vitamin D on the immunopathophysiology, disease activity, and extra-musculoskeletal manifestations of systemic lupus erythematosus. Int J Mol Sci. 2018;19(8). https://doi. org/10.3390/ijms19082355.

44. Nguyen MH, Bryant K, O'Neill SG. Vitamin D in SLE: a role in pathogenesis and fatigue? A review of the literature. Lupus. 
2018;27(13):2003-11.https://doi.org/10.1177/ 0961203318796293.

45. Wang Y, Zhu J, DeLuca HF. Where is the vitamin D receptor? Arch Biochem Biophys. 2012;523(1):123-33. https://doi.org/10. 1016/j.abb.2012.04.001.

46. Sabio JM, Vargas-Hitos JA, Martinez Bordonado J, MediavillaGarcia JD. Association between non-dipper hypertension and vitamin D deficiency in women with systemic lupus erythematosus. Clin Exp Rheumatol. 2018.

47. Douma LG, Gumz ML. Circadian clock-mediated regulation of blood pressure. Free Radic Biol Med. 2018;119:108-14. https:// doi.org/10.1016/j.freeradbiomed.2017.11.024.

48. Norlander AE, Madhur MS, Harrison DG. The immunology of hypertension. J Exp Med. 2018;215(1):21-33. https://doi.org/10. 1084/jem.20171773.

49. Crislip GR, Sullivan JC. T-cell involvement in sex differences in blood pressure control. Clin Sci (London, England : 1979). 2016;130(10):773-83. https://doi.org/10.1042/cs20150620.

50. Caillon A, Paradis P, Schiffrin EL. Role of immune cells in hypertension. Br J Pharmacol. 2018. https://doi.org/10.1111/bph.14427.

51. Scott JL, Wirth JR, Eudaly J, Ruiz P, Cunningham MA. Complete knockout of estrogen receptor alpha is not directly protective in murine lupus. Clin Immunol. 2017;183:132-41. https://doi.org/ 10.1016/j.clim.2017.08.010 This study challenges the concept that estrogen receptor alpha knockout is protective against renal disease in murine lupus. The authors demonstrate that genetic knockout of estrogen receptor alpha does not protect against lupus development in mice, and that ovariectomy with estradiol repletion did not confer any protection. These data suggest that other ovarian hormones may confer protection.

52. Ramirez LA, Sullivan JC. Sex differences in hypertension: where we have been and where we are going. Am J Hypertens. 2018;31: 1247-54. https://doi.org/10.1093/ajh/hpy148.

53. Gilbert EL, Mathis KW, Ryan MJ. 17beta-estradiol protects against the progression of hypertension during adulthood in a mouse model of systemic lupus erythematosus. Hypertension. 2014;63(3):616 23. https://doi.org/10.1161/HYPERTENSIONAHA.113.02385.

54. Gilbert EL, Ryan MJ. Impact of early life ovariectomy on blood pressure and body composition in a female mouse model of systemic lupus erythematosus. Am J Physiol Regul Integr Comp Physiol. 2014;307(8):R990-7. https://doi.org/10.1152/ajpregu.00038.2014.

55. Margiotta D, Navarini L, Vadacca M, Basta F, Lo Vullo M, Pignataro F, et al. Relationship between leptin and regulatory $\mathrm{T}$ cells in systemic lupus erythematosus: preliminary results. Eur Rev Med Pharmacol Sci. 2016;20(4):636-41.

56. Abella V, Scotece M, Conde J, López V, Lazzaro V, Pino J, et al. Adipokines, metabolic syndrome and rheumatic diseases. J Immunol Res. 2014;2014:343746-14. https://doi.org/10.1155/ 2014/343746

57. Bravo PE, Morse S, Borne DM, Aguilar EA, Reisin E. Leptin and hypertension in obesity. Vasc Health Risk Manag. 2006;2(2):163-9.

58. Tian G, Liang JN, Wang ZY, Zhou D. Emerging role of leptin in rheumatoid arthritis. Clin Exp Immunol. 2014;177(3):557-70. https://doi.org/10.1111/cei.12372.

59. Wang X, Qiao Y, Yang L, Song S, Han Y, Tian Y, et al. Leptin levels in patients with systemic lupus erythematosus inversely correlate with regulatory T cell frequency. Lupus. 2017;26(13): 1401-6. https://doi.org/10.1177/0961203317703497 Data suggest that leptin is increased in SLE patients compared to controls, particularly in SLE patients with moderate and sever active disease. Increased leptin levels correlated with disease activity and were inversely correlated with the frequency of $T_{\text {REG }}$ cells in SLE patients but not in controls.

60. Mathis KW, Wallace K, Flynn ER, Maric-Bilkan C, LaMarca B, Ryan MJ. Preventing autoimmunity protects against the development of hypertension and renal injury. Hypertension. 2014;64(4):792-800. https://doi.org/10.1161/HYPERTENSIONAHA.114.04006.

61. Alshaiki F, Obaid E, Almuallim A, Taha R, El-Haddad H, Almoallim H. Outcomes of rituximab therapy in refractory lupus: a meta-analysis. Eur J Rheumatol. 2018;5(2):118-26. https://doi. org/10.5152/eurjrheum.2018.17096.

62. Karasawa K, Uchida K, Takabe T, Moriyama T, Nitta K. Recent advances in treatment strategies for lupus nephritis. Contrib Nephrol. 2018;195:42-50. https://doi.org/10.1159/000486933.

63. Herrera J, Ferrebuz A, MacGregor EG, Rodriguez-Iturbe B. Mycophenolate mofetil treatment improves hypertension in patients with psoriasis and rheumatoid arthritis. J Am Soc Nephrol. 2006;17(12 Suppl 3):S218-25. https://doi.org/10.1681/asn. 2006080918.

64. Neubert K, Meister S, Moser K, Weisel F, Maseda D, Amann K, Wiethe C, Winkler TH, Kalden JR, Manz RA, and Voll RE. The proteasome inhibitor bortezomib depletes plasma cells and protects mice with lupus-like disease from nephritis. Nature medicine 2008;14:748-755.

65. Bagavant H, Tung KS. Failure of CD25+ T cells from lupus-prone mice to suppress lupus glomerulonephritis and sialoadenitis. J Immunol. 2005;175(2):944-50.

66. Crispin JC, Martinez A, Alcocer-Varela J. Quantification of regulatory $\mathrm{T}$ cells in patients with systemic lupus erythematosus. J Autoimmun. 2003;21(3):273-6.

67. Liu MF, Wang CR, Fung LL, Wu CR. Decreased CD4+CD25+ T cells in peripheral blood of patients with systemic lupus erythematosus. Scand J Immunol. 2004;59(2):198-202.

68. Valencia X, Yarboro C, Illei G, Lipsky PE. Deficient CD4+ CD25high T regulatory cell function in patients with active systemic lupus erythematosus. J Immunol. 2007;178(4):2579-88.

69. Wu HY, Staines NA. A deficiency of CD4+CD25+ T cells permits the development of spontaneous lupus-like disease in mice, and can be reversed by induction of mucosal tolerance to histone peptide autoantigen. Lupus. 2004;13(3):192-200. https://doi.org/10. 1191/0961203303lu1002oa.

70. Yan B, Ye S, Chen G, Kuang M, Shen N, Chen S. Dysfunctional $\mathrm{CD} 4+, \mathrm{CD} 25+$ regulatory T cells in untreated active systemic lupus erythematosus secondary to interferon-alpha-producing antigenpresenting cells. Arthritis Rheum. 2008;58(3):801-12. https:// doi.org/10.1002/art.23268.

71. Scalapino KJ, Tang Q, Bluestone JA, Bonyhadi ML, Daikh DI. Suppression of disease in New Zealand Black/New Zealand White lupus-prone mice by adoptive transfer of ex vivo expanded regulatory T cells. J Immunol. 2006;177(3):1451-9.

72. Barhoumi T, Kasal DA, Li MW, Shbat L, Laurant P, Neves MF, et al. T regulatory lymphocytes prevent angiotensin II-induced hypertension and vascular injury. Hypertension. 2011;57(3):469 76. https://doi.org/10.1161/HYPERTENSIONAHA.110.162941.

73. Mian MO, Barhoumi T, Briet M, Paradis P, Schiffrin EL. Deficiency of T-regulatory cells exaggerates angiotensin II-induced microvascular injury by enhancing immune responses. J Hypertens. 2016;34(1): 97-108. https://doi.org/10.1097/HJH.0000000000000761.

74. Matrougui K, Abd Elmageed Z, Kassan M, Choi S, Nair D, Gonzalez-Villalobos RA, et al. Natural regulatory T cells control coronary arteriolar endothelial dysfunction in hypertensive mice. Am J Pathol. 2011;178(1):434-41. https://doi.org/10.1016/j. ajpath.2010.11.034.

75. Kuhn C, Weiner HL. Therapeutic anti-CD3 monoclonal antibodies: from bench to bedside. Immunotherapy. 2016;8(8):889-906. https://doi.org/10.2217/imt-2016-0049.

76. Liu Y, Deng W, Meng Q, Qiu X, Sun D, Dai C. CD8+iTregs attenuate glomerular endothelial cell injury in lupus-prone mice through blocking the activation of p38 MAPK and NF-kappaB. Mol Immunol. 2018;103:133-43. https://doi.org/10.1016/j. molimm.2018.09.006. 
77. Norlander AE, Saleh MA, Kamat NV, Ko B, Gnecco J, Zhu L, et al. Interleukin-17A regulates renal sodium transporters and renal injury in angiotensin II-induced hypertension. Hypertension. 2016;68(1): 167-74. https://doi.org/10.1161/hypertensionaha.116.07493.

78. Sodergren A, Karp K, Boman K, Eriksson C, Lundstrom E, Smedby $\mathrm{T}$, et al. Atherosclerosis in early rheumatoid arthritis: very early endothelial activation and rapid progression of intima media thickness. Arthritis Res Ther. 2010;12(4):R158. https://doi.org/10.1186/ar3116.

79. Mak A, Kow NY, Schwarz H, Gong L, Tay SH, Ling LH. Endothelial dysfunction in systemic lupus erythematosus - a casecontrol study and an updated meta-analysis and meta-regression. Sci Rep. 2017;7(1):7320. https://doi.org/10.1038/s41598-017-07574-1.

80. Vazquez-Del Mercado M, Gomez-Banuelos E, Chavarria-Avila E, Cardona-Munoz E, Ramos-Becerra C, Alanis-Sanchez A, et al. Disease duration of rheumatoid arthritis is a predictor of vascular stiffness: a cross-sectional study in patients without known cardiovascular comorbidities: a STROBE-compliant article. Medicine (Baltimore). 2017;96(33):e7862. https://doi.org/10.1097/MD. 0000000000007862 .

81. Yong WC, Sanguankeo A, Upala S. Association between primary Sjogren's syndrome, arterial stiffness, and subclinical atherosclerosis: a systematic review and meta-analysis. Clin Rheumatol. 2018. https://doi.org/10.1007/s10067-018-4265-1.

82. Tesar V, Masek Z, Rychlik I, Merta M, Bartunkova J, Stejskalova A, et al. Cytokines and adhesion molecules in renal vasculitis and lupus nephritis. Nephrol Dial Transplant. 1998;13(7):1662-7.

83. Bijl M. Endothelial activation, endothelial dysfunction and premature atherosclerosis in systemic autoimmune diseases. Neth J Med. 2003;61(9):273-7.

84. Collins T, Read MA, Neish AS, Whitley MZ, Thanos D, Maniatis T. Transcriptional regulation of endothelial cell adhesion molecules: NF-kappa B and cytokine-inducible enhancers. FASEB J. 1995;9(10):899-909.

85. Lewis MJ, Vyse S, Shields AM, Zou L, Khamashta M, Gordon $\mathrm{PA}$, et al. Improved monitoring of clinical response in systemic lupus erythematosus by longitudinal trend in soluble vascular cell adhesion molecule-1. Arthritis Res Ther. 2016;18:5. https://doi. org/10.1186/s13075-015-0896-7.

86. Molad Y, Miroshnik E, Sulkes J, Pitlik S, Weinberger A, Monselise Y. Urinary soluble VCAM-1 in systemic lupus erythematosus: a clinical marker for monitoring disease activity and damage. Clin Exp Rheumatol. 2002;20(3):403-6.

87. Spronk PE, Bootsma H, Huitema MG, Limburg PC, Kallenberg CG. Levels of soluble VCAM-1, soluble ICAM-1, and soluble Eselectin during disease exacerbations in patients with systemic lupus erythematosus (SLE); a long term prospective study. Clin Exp Immunol. 1994;97(3):439-44.

88. Nakatani K, Fujii H, Hasegawa H, Terada M, Arita N, Ito MR, et al. Endothelial adhesion molecules in glomerular lesions: association with their severity and diversity in lupus models. Kidney Int. 2004;65(4): 1290-300. https://doi.org/10.1111/j.1523-1755.2004.00537.x.

89. Bomback AS, Appel GB. Updates on the treatment of lupus nephritis. J Am Soc Nephrol. 2010;21(12):2028-35. https://doi.org/ 10.1681/asn.2010050472.

90. Bomback AS. Nonproliferative forms of lupus nephritis: an overview. Rheum Dis Clin N Am. 2018;44(4):561-9. https://doi.org/ 10.1016/j.rdc.2018.06.003.

91. Avar Aydin PO, Shan J, Brunner HI, Mitsnefes MM. Blood pressure control over time in childhood-onset systemic lupus erythematous. Lupus. 2018;27(4):657-64. https://doi.org/10.1177/ 0961203317751061.

92. Nakano M, Ueno M, Hasegawa H, Watanabe T, Kuroda T, Ito S, et al. Renal haemodynamic characteristics in patients with lupus nephritis. Ann Rheum Dis. 1998;57(4):226-30.

93. Mori S, Yoshitama T, Hirakata N, Ueki Y. Prevalence of and factors associated with renal dysfunction in rheumatoid arthritis patients: a cross-sectional study in community hospitals. Clin Rheumatol. 2017;36(12):2673-82. https://doi.org/10.1007/ s10067-017-3804-5.

94. Hickson LJ, Crowson CS, Gabriel SE, McCarthy JT, Matteson EL. Development of reduced kidney function in rheumatoid arthritis. Am J Kidney Dis. 2014;63(2):206-13. https://doi.org/10. 1053/j.ajkd.2013.08.010.

95. Franco M, Tapia E, Santamaría J, Zafra I, García-Torres R, Gordon KL, et al. Renal cortical vasoconstriction contributes to development of salt-sensitive hypertension after angiotensin II exposure. J Am Soc Nephrol. 2001;12(11):2263-71.

96. Venegas-Pont M, Mathis KW, Iliescu R, Ray WH, Glover PH, Ryan MJ. Blood pressure and renal hemodynamic responses to acute angiotensin II infusion are enhanced in a female mouse model of systemic lupus erythematosus. Am J Physiol Regul Integr Comp Physiol. 2011;301(5):R1286-92. https://doi.org/10. 1152/ajpregu.00079.2011.

97. Yue C, Li G, Wen Y, Li X, Gao R. Early renin-angiotensin system blockade improved short-term and long-term renal outcomes in systemic lupus erythematosus patients with antiphospholipidassociated nephropathy. J Rheumatol. 2018;45(5):655-62. https://doi.org/10.3899/jrheum.170561.

98. Lightfoot YL, Blanco LP, Kaplan MJ. Metabolic abnormalities and oxidative stress in lupus. Curr Opin Rheumatol. 2017;29(5): 442-9. https://doi.org/10.1097/BOR.0000000000000413.

99. Sinha N, Dabla PK. Oxidative stress and antioxidants in hypertension-a current review. Curr Hypertens Rev. 2015;11(2): 132-42.

100. Glennon-Alty L, Hackett AP, Chapman EA, Wright HL. Neutrophils and redox stress in the pathogenesis of autoimmune disease. Free Radic Biol Med. 2018;125:25-35. https://doi.org/ 10.1016/j.freeradbiomed.2018.03.049.

101. Villanueva E, Yalavarthi S, Berthier CC, Hodgin JB, Khandpur R, Lin AM, et al. Netting neutrophils induce endothelial damage, infiltrate tissues, and expose immunostimulatory molecules in systemic lupus erythematosus. J Immunol. 2011;187(1):538-52. https://doi.org/10.4049/jimmunol.1100450.

102. Liu Y, Kaplan MJ. Cardiovascular disease in systemic lupus erythematosus: an update. Curr Opin Rheumatol. 2018;30(5):441-8. https://doi.org/10.1097/bor.0000000000000528.

103. Carmona-Rivera C, Kaplan MJ. Low-density granulocytes: a distinct class of neutrophils in systemic autoimmunity. Semin Immunopathol. 2013;35(4):455-63. https://doi.org/10.1007/ s00281-013-0375-7 This study tested the hypothesis that SLE patients have impaired clearance of neutrophil extracellular traps (NETs) that contributes to the pathogenesis of lupus nephritis. Data suggest that sera from a subset of SLE patients degraded NETs poorly due to the presence of DNase1 inhibitors or anti-NET antibodies that prevent DNase1 access to NETs. Impaired DNase1 function and NET degradtion correlated with renal involement in this patient population.

104. Hakkim A, Furnrohr BG, Amann K, Laube B, Abed UA, Brinkmann $\mathrm{V}$, et al. Impairment of neutrophil extracellular trap degradation is associated with lupus nephritis. Proc Natl Acad Sci U S A. 2010;107(21):9813-8. https://doi.org/10.1073/pnas.0909927107.

105. Lee HT, Wu TH, Lin CS, Lee CS, Wei YH, Tsai CY, et al. The pathogenesis of systemic lupus erythematosus - from the viewpoint of oxidative stress and mitochondrial dysfunction. Mitochondrion. 2016;30:1-7. https://doi.org/10.1016/j.mito.2016.05.007.

106. Forbes JM, Thorburn DR. Mitochondrial dysfunction in diabetic kidney disease. Nat Rev Nephrol. 2018;14(5):291-312. https:// doi.org/10.1038/nrneph.2018.9.

107. Perl A, Hanczko R, Doherty E. Assessment of mitochondrial dysfunction in lymphocytes of patients with systemic lupus erythematosus. Methods Mol Biol (Clifton, NJ). 2012;900:61-89. https://doi.org/10.1007/978-1-60761-720-4_4. 